\title{
Preparing to fight back: generation and storage of priming compounds
}

\author{
Victoria Pastor ${ }^{1}$, Andrea Balmer ${ }^{1}$, Jordi Gamir ${ }^{2}$, Victor Flors ${ }^{2 *}$ and Brigitte Mauch-Mani ${ }^{1 *}$ \\ 1 Institute of Biology Laboratory of Molecular and Cell Biology, University of Neuchâtel, Neuchâtel, Switzerland \\ ${ }^{2}$ Metabolic Integration and Cell Signaling Group, Plant Physiology Section, Department of CAMN, Universitat Jaume I, Castellon, Spain
}

\author{
Edited by: \\ Andrés A. Borges, Consejo Superior \\ de Investigaciones Científicas, Spain \\ Reviewed by: \\ Corné M. J. Pieterse, Utrecht \\ University, Netherlands \\ Marino Exposito Rodriguez, Exeter \\ University, UK \\ *Correspondence: \\ Victor Flors, Department of CAMN, \\ Universitat Jaume I, Avd. Vicent Sos \\ Baynat s/n. 12071 Castellón, Spain \\ e-mail: flors@uji.es; \\ Brigitte Mauch-Mani, Unimail, \\ University of Neuchâtel, LBCM, Rue \\ Emile Argand 112000 Neuchâtel, \\ Switzerland \\ e-mail: brigitte.mauch@unine.ch
}

Immune-stimulated plants are able to respond more rapidly and adequately to various biotic stresses allowing them to efficiently combat an infection. During the priming phase, plant are stimulated in absence of a challenge, and can accumulate and store conjugates or precursors of molecules as well as other compounds that play a role in defense. These molecules can be released during the defensive phase following stress. These metabolites can also participate in the first stages of the stress perception. Here, we report the metabolic changes occuring in primed plants during the priming phase. $\beta$-aminobutyric acid (BABA) causes a boost of the primary metabolism through the tricarboxylic acids (TCA) such as citrate, fumarate, (S)-malate and 2-oxoglutarate, and the potentiation of phenylpropanoid biosynthesis and the octodecanoic pathway. On the contrary, Pseudomonas syringae pv tomato (PstAvrRpt2) represses the same pathways. Both systems used to prime plants share some common signals like the changes in the synthesis of amino acids and the production of SA and its glycosides, as well as IAA. Interestingly, a product of the purine catabolism, xanthosine, was found to accumulate following both BABA- and PstAvrRpt2-treatement. The compounds that are strongly affected in this stage are called priming compounds, since their effect on the metabolism of the plant is to induce the production of primed compounds that will help to combat the stress. At the same time, additional identified metabolites suggest the possible defense pathways that plants are using to get ready for the battle.

Keywords: priming, $\beta$-aminobutyric acid (BABA), metabolites, primary metabolism, amino acids, induced resistance

\section{INTRODUCTION}

Plants are generally confined to one location for their whole lifetime and had therefore to develop adaptive and defensive mechanisms against biotic and abiotic stresses that take this limitation into account. The first crucial step for a plant is to recognize that it is attacked (Nimchuk et al., 2003). The speed by which the plant senses and accurately recognizes a specific stress(or) determines how appropriate and successful its reaction will be. Failure to mount a timely or fitting response will, in case of pathogen attack, lead to colonization of the host tissues and hence to disease (Ebel and Cosio, 1994; Jones and Takemoto, 2004). This basal immunity of a plant contributes to slowing down the colonization process but is generally too weak to effectively prevent disease (Nürnberger and Lipka, 2005). The level of basal immunity of a plant, however, can be enhanced through application of appropriate stimuli. This is commonly referred to as induced resistance (IR). Plants have acquired the ability to widely improve their defensive capacity against a broad range of pathogens including viruses, fungi, oomycetes, and bacteria toward which they are genetically speaking susceptible (Durrant and Dong, 2004; Hammerschmidt, 2009). This defense has to be triggered by an inducing treatment. Various such treatments have been shown to successfully induce resistance. They consist among others of an inoculation with pathogens, rhizobacteria or a treatment with defined chemicals and lead to horizontal resistance of the plant against a broad range of pathogenic organisms (van Loon et al., 1998; Oostendorp et al., 2001; Cohen, 2002; Hammerschmidt, 2009). This resistance operates in all plant parts distant from the original locus of inoculation and is therefore called systemic resistance (Durrant and Dong, 2004).

The initial phase of resistance induction, where the plant is preparing for a future attack but has not yet been challenged by a pathogen is called the priming phase (Conrath et al., 2002). Priming leads to a physiological state in which a plant responds faster and/or more accurately to an attack (Prime-A-Plant Group et al., 2006). This phase lies between the perception of the priming cue and the first exposure to a future stress. During this time slot the plant has to generate and store information that will enable it to deploy this faster and/or more accurate response to stress. How a plant senses and translates a priming cue is not known, however, there is a lot of information on what stimuli successfully induce the priming state. They reach from avirulent pathogens, insect pests, microbe- and host-derived molecules, synthetic substances up to metabolic disturbances of the plant and abiotic stressors (Prime-A-Plant Group et al., 2006). This large diversity in priming triggers suggests that multiple approaches could 
lead to the induction of the priming state. There is evidence that some of these primary stimuli target epigenetic mechanisms (Bruce et al., 2007). It had been suggested that histone modification and histone replacement could take place at the onset of priming (van den Burg and Takken, 2009). In the meantime it has been shown that the induction of JA-dependent defenses through infection with Alternaria brassicicola and Botrytis cinerea or by JA itself leads to histone methylation in the promotors of JA-inducible genes (Berr et al., 2010). In rice, JMJ705 codes for a histone lysine demethylase that is induced upon pathogen infection. Overexpression of this histone demethylase results in an increase of resistance against bacterial blight (Li et al., 2013). An association of SA-dependent defenses with NPR1-dependent post-translational modifications of histone tails in promotors of genes coding for defense-related TFs has also been reported (Jaskiewicz et al., 2011). All this hints to an implication of epigenetic mechanisms right at the onset of priming.

There is not much information available on the actual priming phase that follows such epigenetic changes. Possible mechanisms underlying the actual priming have recently been reviewed (Pastor et al., 2013a). The earlier proposition that the priming process is associated with an accumulation of inactive protein kinases has been substantiated by the fact that treatment with the SAR inducer benzo(1,2,3) thiadiazole-7-carbothioic acid S-methyl ester (BTH) leads to an accumulation of inactive MAP kinase 3 (MPK3) and MPK6 (Beckers et al., 2009). Induction of resistance by $\beta$-aminobutyric acid (BABA) and the concomitant priming of SA-dependent defenses correlates with a higher expression of SA-regulatory transcription factor (TF) genes and priming with rhizobacteria (WCS417r) leads to an enhanced expression of jasmonic acid (JA)-TF regulatory genes (Van der Ent et al., 2009). The mentioned inactive protein kinases could then be rapidly activated upon stress exposure and the availability of the TF allow for a more effective defense signaling. Hence, both mechanisms could possibly contribute to a faster reaction of the plant.

Plants have also been shown to accumulate inactive defensemetabolite conjugates in their vacuoles that could be released upon attack. Well-known examples are the phytoanticipins glycosinolates and benzoxazinoids, both released into an active form upon hydrolysation with glucosidases (Morant et al., 2008). Plant hormone conjugates could also play a role in priming. Methylated and glucosylated abscisic acid (ABA)-conjugates are mainly stored in vacuoles (Kaiser et al., 1985) and free ABA is then released upon contact with apoplastic esterases (Sauter et al., 2002). During infection of tobacco plants, the induced salicylic acid (SA) is partially metabolized into SA 2-O- beta-D-glucose (SAG) by a SA glucosyltransferase (SAGT) (Edwards, 1994; Lee and Raskin, 1998, 1999; Dean and Mills, 2004; Dean et al., 2005; Song, 2006). Such bound SA could be rapidly liberated through the action of a beta-glucosidase (Seo et al., 1995) when the plant is challenged (Dean et al., 2005). Interestingly, an Arabidopsis mutant impaired in SAG and SEG (ugt74f1) is more susceptible to infection by Pseudomonas syringae pv tomato (Pst) than its wild type counterpart (Boachon et al., 2014) and is partially blocked in BABA-IR against Pst (Flors and Mauch-Mani, unpublished). In maize plants, it was shown that following resistance induction with the hemibiotrophic fungus Colletotrichum graminicola, the plants accumulate an array of metabolites comprising, besides the well-described benzoxazinoids, molecules such as apigenin, genkwanin, and chlorogenic acid with known fungicidal effects. Interestingly, the reaction of maize to priming treatment was shown to be organ-specific (Balmer et al., 2012; Balmer and Mauch-Mani, 2013).

The specific events targeted by priming (the primed mechanisms) depend on the attacker or stress to be countered. Among these early events are the control of stomatal closure in defense against pathogens using stomata as their entry point into the plant (Jakab et al., 2005), the generation of reactive oxygen species (Moller et al., 2007; Trouvelot et al., 2008; Pastor et al., 2013b), interference with effector-triggered susceptibility (Jones and Dangl, 2006) or callose deposition at the attempted points of entry (Garcia-Andrade et al., 2011). At later time points, priming can influence hormonal signaling pathways such SA-, JA, ABA-, and ET signaling (Ton and Mauch-Mani, 2004; Flors et al., 2008; Jung et al., 2009; Van der Ent et al., 2009; Conrath, 2011; Rasmann et al., 2012). While interactions with biotrophic pathogens are generally controlled via the SA pathway, necrotrophic pathogens and insects are rather contained by mechanisms depending on JA/ET signaling (Glazebrook, 2005). The ABA pathway on the other hand plays an important role in protective mechanisms involving callose deposition or stomatal closure (Ton and MauchMani, 2004; Jakab et al., 2005; Hamiduzzaman et al., 2005; Ton et al., 2009).

More sensitive chromatographic techniques make it now possible to identify metabolites that accumulate during the priming phase as well as in the phase following challenge by a stressor (priming vs. primed metabolites). Several secondary metabolites that mediate priming have recently been identified. Among them figure azelaic acid (Jung et al., 2009), imprimatins (Noutoshi et al., 2012), indol-3-carboxilic acid (I3CA; Gamir et al., 2012), pipecolic acid (Návarová et al., 2012) or galacturonic acid and hypoxanthine (Gamir et al., 2014).

The aim of the present study was to establish a metabolomic profiling of the priming phase of Arabidopsis thaliana following induction of priming by two different priming cues, i.e., priming by inoculation with avirulent Pseudomonas and chemical priming by soil-drench with BABA. The ultimate goal was to determine whether different priming stimulus can prepare the plant during the priming phase activating common/different metabolic pathways.

\section{MATERIALS AND METHODS BIOLOGICAL MATERIAL}

Arabidopsis accession Col-0 seeds were germinated in soil and maintained at $21^{\circ} \mathrm{C}$ day $/ 18^{\circ} \mathrm{C}$ night, with $9 \mathrm{~h}$ of light $(125 \mu \mathrm{E}$ $\mathrm{m}^{-2} \mathrm{~s}^{-1}$ ) and $60 \%$ of relative humidity. One week after germination seedlings were individually transferred to $33 \mathrm{~mL}$ Jiffy pellets and kept in the same conditions until the treatments. The experiments were performed with 4-5 weeks-old plants. The avirulent strain Pseudomonas syringae pv tomato DC3000 (PstAvrRpt2) was grown overnight in liquid medium King $B$ with antibiotics rifampicin $\left(50 \mu \mathrm{g} \times \mathrm{mL}^{-1}\right)$ and kanamicin $\left(25 \mu \mathrm{g} \times \mathrm{mL}^{-1}\right)$ for selection. 


\section{PLANT TREATMENTS, SAMPLING, AND METABOLITE EXTRACTION}

Col-0 plants were soil-drenched with $250 \mu \mathrm{M}$ of BABA (as a final concentration) or water (as control). For the avirulent strain PstAvrRpt2, 2-3 leaves of plants of the same age as for the BABA treatments (4-5 weeks old) were dip-inoculated in the bacterial suspension of $10^{9}$ colony-forming units $\mathrm{mL}^{-1}$ in $10 \mathrm{mM}$ of $\mathrm{MgSO}_{4}$ and $0.01 \%$ of Silwet L-77 for $4 \mathrm{~s}$, or in the same solution without bacteria (as a control). Samples were taken at 24 and $48 \mathrm{hpt}, 3-4 \mathrm{~h}$ after the onset of the light phase. The material was lyophilized, extracted in $\mathrm{MeOH} 10 \%$ and further processed as described in Gamir et al. (2012).

To ensure that the plants used for the experiments were primed, for each experiment sample plants were challenged with virulent Pseudomonas syringae pv tomato (Pst) at a concentration of $10^{5}$ colony-forming units (cfu). $\mathrm{mL}^{-1}$ as described previously (Slaughter et al., 2012). The disease phenotype was assessed 5 days after challenge and expressed as number of symptomatic leaves.

\section{LC-ESI FULL SCAN MASS SPECTROMETRY (0-TOF INSTRUMENT)}

Metabolome analysis was performed using an Acquity UPLC system (Waters, Mildford, MA, USA) interfaced to hybrid quadrupole time-of-flight (QTOF MS Premier). The LC separation was performed by HPLC SunFire C18 analytical column, $5 \mu \mathrm{m}$ particle size, $2.1 \times 100 \mathrm{~mm}$ (Waters). Analytes were eluted with a gradient of methanol and water containing $0.01 \%$ $\mathrm{HCOOH}$. Chromatographic conditions and QTOF MS parameters were followed as described in Gamir et al. (2012).

\section{FULL SCAN DATA ANALYSIS}

Raw data obtained from Masslynx software was transformed to .CDF using Databrigde provided by Masslynx package. The .CDF data was process with $\mathrm{R}$ for statistical computing using XCMS package for relative quantification (Smith et al., 2006). For Principal Component Analysis (PCA), heatmap construction and clustering of metabolite the software MarVis Filter and MarVis cluster (http://marvis.gobics.de/; Kaever et al., 2012) were used. The most prominently induced compounds and others shown in text were subjected to identification (Table $\mathbf{1}$ ) and the relative intensity of accumulation was analyzed using a paired nonparametric Wilcoxon Mann-Whitney test to confirm a significant difference between the samples $(P<0.05)$.

\section{RESULTS}

\section{DIFFERENT PRIMING STIMULI IMPOSE SUBTLE METABOLIC CHANGES IN THE ABSENCE OF CHALLENGE}

The primed state can be induced by various agents. In order to differentiate between chemical and biological induction, BABA was used as a chemical inducer (Zimmerli et al., 2000; Jakab et al., 2001; Ton and Mauch-Mani, 2004) and the avirulent bacterium Pseudomonas syringae carrying the avirulence gene AvrRpt2 (PstAvrRpt2; Mudgett and Staskawicz, 1999) as a biological inducer of resistance. Since metabolites are the final products resulting from metabolic pathways, the present work aims to identify, the main compounds that could act as signals during the priming phase and the involved pathways. It is presumed that at first contact with BABA or PstAvrRpt2 a plant response is initiated that will allow it to get ready to combat further stresses. To
Table 1 | List of compounds identified by exact mass and fragmentation spectrum.

\begin{tabular}{lcccc}
\hline Compound & Mass (neutral) & Fragments & ESI & RT (min) \\
\hline Citrate/isocitrate & 192.027 & $111.010,87.011$ & - & 2.81 \\
Fumarate & 116.013 & 71.0148 & - & 3.06 \\
S-Malate & 134.022 & $115.005,89.027$ & - & 1.81 \\
Succinate & 118.029 & 73.032 & - & 1.43 \\
2-Oxoglutarate & 146.023 & $101.026,73.016$ & - & 4.30 \\
9(S)-HPOT/2(R)- & 310.214 & $309.106,291.185$ & - & 12.90 \\
HPOT & & & & \\
13(S)-HOT & 294.184 & $236.106,221.157$ & - & 12.40 \\
OPC-8:0/9(S)- & 294.217 & $275.202,96.962$ & - & 13.18 \\
HOT & & & & \\
13 (S)-HODE & 296.234 & 71.018 & - & 13.37 \\
Sinapate & 224.069 & $208.03,93.037$ & - & 8.50 \\
Sinapoyl malate & 340.0806 & $223.063,133.015$ & - & 9.41 \\
1-O-Sinapoyl- $\beta-$ & 386.122 & $223.065,190.026$ & - & 3.48 \\
D-glucose & & 151.029 & - & 1.81 \\
Xanthosine & 284.077 & 133.016 & - & 1.52 \\
Guanosine & 283.093 & &
\end{tabular}

9(S)-HPOT, (10E, 12Z,15Z)-(9S)-9-Hydroperoxyoctadeca-10,12,15-trienoic acid; 2(R)-HPOT, (2R)-(9Z,12Z, 15Z)-2-Hydroperoxyoctadecatri-9, 12,15-enoic acid; 13 (S)-HOT, (9Z,11E, 15Z)-(13S)-Hydroxyoctadeca-9, 11, 15-trienoate; OPC-8:0, 8-[(1R,2R)-3-Oxo-2-\{(Z)-pent-2-enyl\}cyclopentyl]octanoate; 9(S)-HOT, (9S)(10E, 12Z, 15Z)-9-Hydroxyoctadecatri-10, 12, 15-enoic acid; 13 (S)-HODE, (13S)Hydroxyoctadecadienoic acid.

ensure that the plants used in our experiments were primed, for each experiment sample plants were challenged and the resulting disease phenotype was assessed (Figure 1).

To this end Arabidopsis Col-0 plants were treated with BABA and PstAvrRpt2 with water- and mock-treated plants as control, respectively. To gain a global overview of the metabolite balance during the priming phase, i.e., the 48 -h time interval before the stress is usually applied (Pastor et al., 2013a and the references within), a metabolic analysis with UPLC coupled to Q-TOF mass spectrometry (quadrupole-time of flight mass spectrometer) was performed. Metabolic and bioinformatic analysis of the signals obtained in positive and negative electrospray ionization (ESI) were done according to the methods of Fernie et al. (2011), Kaever et al. (2012), and Gamir et al. (2014). When comparing the four groups (Figure 2; water, BABA, mock, and PstAvrRpt2) the principal component analysis (PCA) shows the global behavior of the signals in both modes of ESI at $24 \mathrm{hpt}$ and $48 \mathrm{hpt}$. BABA and PstAvrRpt2 both induce qualitative different metabolites, easily visualized in the cluster realized by the Marvis Cluster software. This might point to at least partially different mechanisms of priming action for BABA and PstAvrRpt2.

Signals found in BABA-treated plants do not overlap but remain close to control plants. This confirms the previous view that priming does not lead to major changes in a plant (Conrath, 2009). The fact that in positive mode the signals are closer than in negative mode means that in general, the compounds that are negatively ionized could be more important in the establishment of priming, since they present a higher difference in respect to 


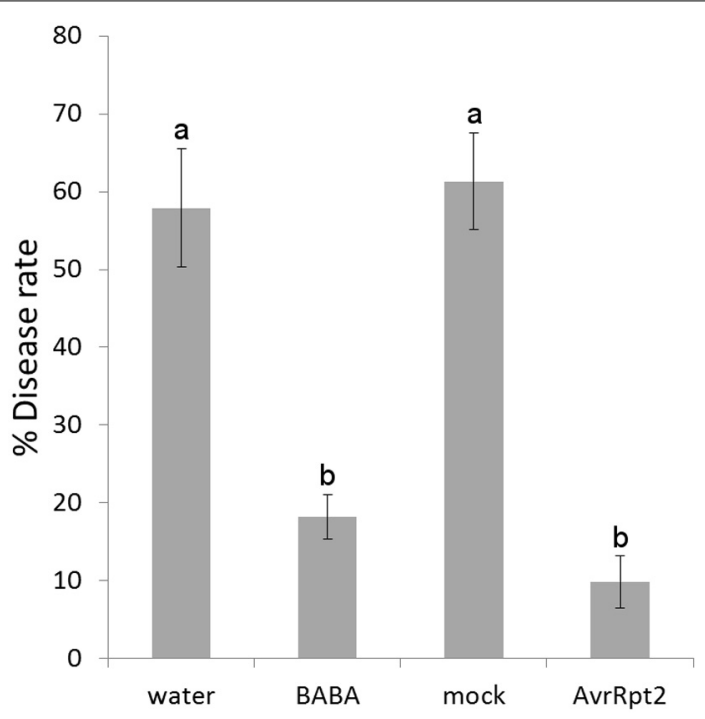

FIGURE 1 | Disease symptoms in Col-0 plants. Arabidopsis plants were inoculated with a bacterial suspension of Pst at $10^{5}$ colony-forming units (cfu). $\mathrm{mL}^{-1}$. Disease symptoms were determined after 5 days of inoculation and quantified as the proportion of leaves with symptoms. The values are means of the percentage of diseased leaves per plant $\pm \mathrm{SD}$. Data presented are from a representative experiment that was repeated for every experiment with similar results. Different letters indicate statistically significant differences between control and infected plants $(p<0.05$, $n=20-25)$

the control. On the contrary, inoculation with avirulent bacteria shows that the action of bacteria is slower than BABA. Separation between bacteria and mock treatment becomes visible only after 48 hpt.

The differences between treatments was visualized through a supervised heatmap analysis using the signals that showed a significant difference (Kruskal-Wallis test $P<0.05$ ). At both 24 and $48 \mathrm{hpt}$, there is more dynamism in the group of compounds stemming from BABA-treated plants than from PstAvrRpt2-inoculated plants. However, when clustering water vs. BABA and mock vs PstAvrRpt2 (Figures S1, S2) the differences between treated and not treated plants are more visible. All together BABA-treatment leads to a more rapid induction of the priming phase than inoculation with bacteria does.

\section{CHEMICAL AND BIOLOGICAL PRIMING TARGETS PRIMARY METABOLISM DURING PRIMING PHASE: THE ROLE OF CARBOXYLIC ACIDS}

Priming is a horizontal phenomenon potentiating basal defenses and further layers of defense in case basal defense is defective (Pastor et al., 2013b). The plant is put in a state of alert allowing a wide elasticity in the use of defenses. Therefore, priming metabolites might be very primary compounds that can be channeled to any direction in order to rapidly strengthen the defensive state of the plant. To determine the most relevant compounds in priming, the most strongly induced signals in the clusters were identified by exact mass, fragmentation spectrum and the retention time of the fragments using the Metlin (http://metlin.scripts.edu) and MassBank (http://www.massbank.jp) databases, and, if necessary, the Kegg and Aracyc databases (http://www.genome.jp/kegg/; http:// pathway.gramene.org/gramene/aracyc.shtml). Interestingly, the most induced compounds by BABA belong to the tricarboxylic acid cycle (TCA). These compounds accumulated to a lesser degree following PstAvrRpt2 infection (Figure 3). Citrate/isocitrate production was strongly induced by BABA at 24 and $48 \mathrm{hpt}$ and, to a lesser extent, also a (S)-Malate, 2-Oxoglutarate and fumarate. Interestingly, PstAvrRpt2 repressed the accumulation of all these compounds. Nevertheless, succinate was less present in plants treated by both types of priming. Hence, BABA-induced priming functions through the potentiation of the TCA cycle, while PstAvrRpt2-induced priming acts differently. All this suggests that the primary metabolism plays an important role in priming for defenses, and is a key point in defining the mechanisms operating in compatible interactions.

\section{CHEMICAL AND BIOLOGICAL PRIMING TARGETS PRIMARY METABOLISM DURING PRIMING PHASE: CHANGES IN AMINO ACIDS}

The compounds involved in TCA flux are the origin for different amino acids pathways. Defense responses against pathogens and insects induce antimicrobial and signaling compounds such as glucosinolates and their breakdown products (Barth and Jander, 2006; Bednarek et al., 2009), or JA-Ile (Fonseca et al., 2009). These secondary metabolites are derivatives or conjugates of amino acids. The balance of amino acids has a major impact on plant defense and priming (Liu et al., 2010; Singh et al., 2010; Návarová et al., 2012; Zeier, 2013; Gamir et al., 2014). In order to know whether these metabolites play a role during the priming phase after BABA and PstAvrRpt2 treatment, the amino acids were identified using a library of amino acids set up with standards (Gamir et al., 2014).

After 24 hpt (Figure 4) BABA-treated plants accumulated Cys, Met, Glu, Ile+Leu (no distinguishable in our chromatographic conditions), His, Thr, Tyr, and Phe. At the same time, the plants primed by avirulent bacteria produced more Cys, Met, and Trp. At the later time point ( $48 \mathrm{hpt}$; Figure 5), the levels of Cys, Met, Glu, and Ile+Leu remained high in BABA-treated plants, Thr and Tyr (these last two in lower amounts), but His and Phe were repressed. Other amino acids like Ala, Ser, Asn, and Lys accumulated at this later time point following BABA-priming. On the other hand, plants incoculated with PstAvrRpt2 kept accumulating Cys, Met, and Trp (this one in higher levels that at $24 \mathrm{hpt}$ ), but showed a reduced accumulation of Arg, Pro, and Tyr however were induced at this time point.

Asp, Gln, and Val are less abundant in all time points, independently of the treatment, while Cys, Met, and later, Tyr, were always accumulating under priming conditions. In general, at the beginning, there was depletion in amino acid accumulation during the priming phase, and this effect was more pronounced at $24 \mathrm{hpt}$.

Thus, the priming state leads to a drop in amino acids during the first hours, and Cys, Met, and Tyr are "priming amino acids" preparing the plant for primed defenses.

\section{PRIMING OF SECONDARY METABOLITES}

Since the primary metabolism seems to play a central role in the establishment of priming, the contribution of the secondary 
A

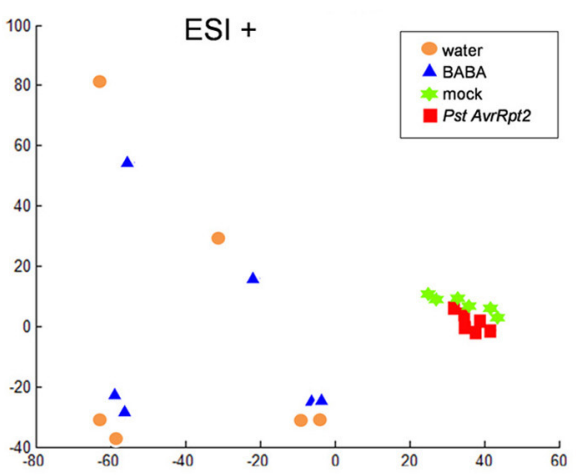

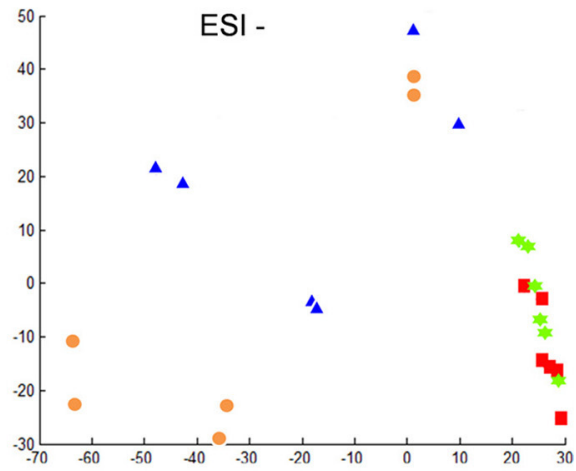

$\mathrm{ESI}+$

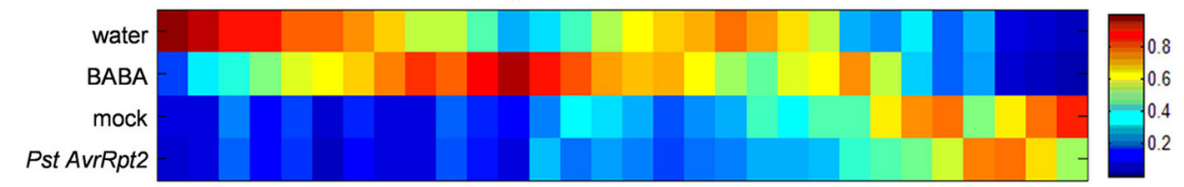

ESI -

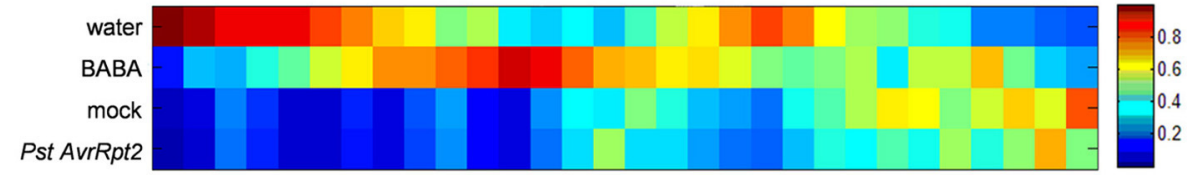

C
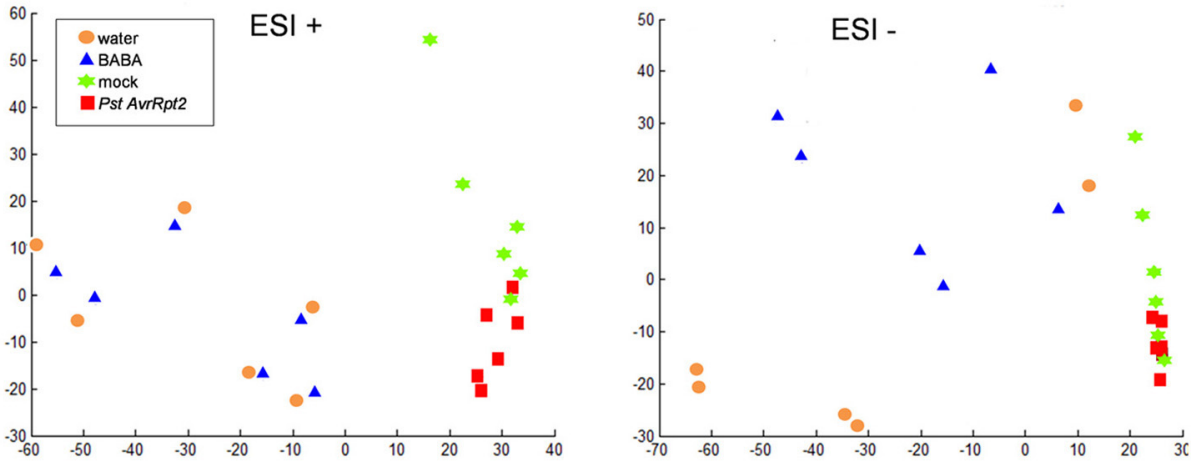

D

$\mathrm{ESI}+$

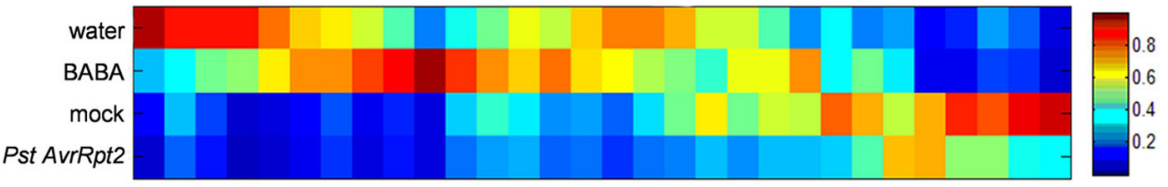

ESI -

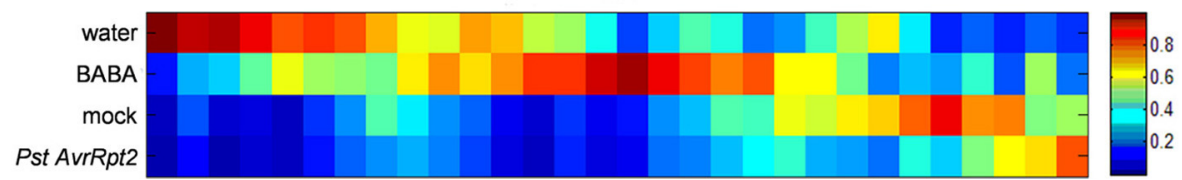

FIGURE 2 | Principal component analysis (PCA) and cluster plots comparing the four groups generated from the major sources of variable signals obtained in $\mathrm{ESI}+$ and $\mathrm{ESI}-$ by non-targeted analysis by HPLC-OTOF MS of the four groups water, BABA, mock, and PstAvrRpt2. The PCA and cluster analyses were performed using Marvis Filter and Cluster packages, following a Kruskal-Wallys test $(p<0.05)$. (A) PCA analysis score plot after $24 \mathrm{hpt}$. (B) Cluster plot of main compounds of the four groups after $24 \mathrm{hpt}$. (C) PCA analysis score plot at $48 \mathrm{hpt}$. (D) Cluster plot of significant compounds after $48 \mathrm{hpt}$ 


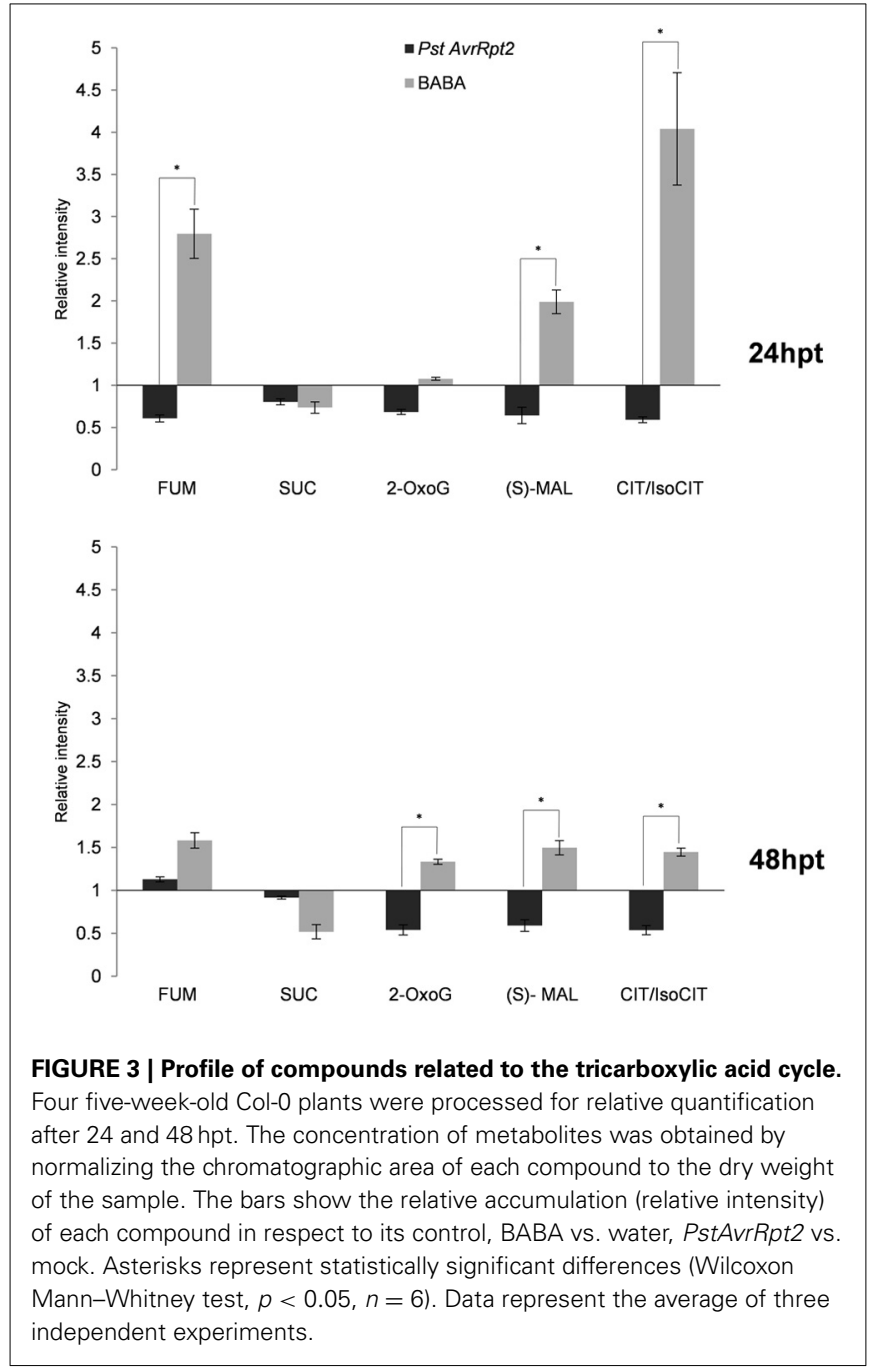

metabolism was also investigated. Using the library of metabolites (see above), some hormones (Figure 5) and indolic compounds (Figure 6) participating in priming were identified.

Free salicylic acid (SA) and glucosides of SA (SAG+SGE) accumulated in both time points and the induction was higher by BABA than avirulent bacteria. Indole-3-acetic acid (IAA) showed higher levels at $24 \mathrm{hpt}$ but decreased afterwards and was repressed by BABA. Additional indolic compounds have been identified, among them indole-3-carboxaldehyde ( $\mathrm{I} 3 \mathrm{CHO}$ ), indole-3-acetamide (IAM), indol-3-pyruvic acid (IPA), indole-3acetyl-L-Ala (IALA), and indole-3-carboxylic acid methyl ester (I3CAME). At $24 \mathrm{hpt}$ all of them showed elevated levels in comparison to the controls. Interestingly, IALA was significantly more present in PstAvrRpt2- treated than in BABA-treated plants. After $48 \mathrm{hpt}$, the situation was different, since in BABA-treated plants the levels of IALA remained elevated but in PstAvrRpt2inoculated plants the accumulation of this conjugate was repressed. In general, PstAvrRpt2 treatment represses the accumulation of most these indolic compounds after $48 \mathrm{hpt}$. When this is not the case, then BABA-treatment leads to a repression of these compounds.

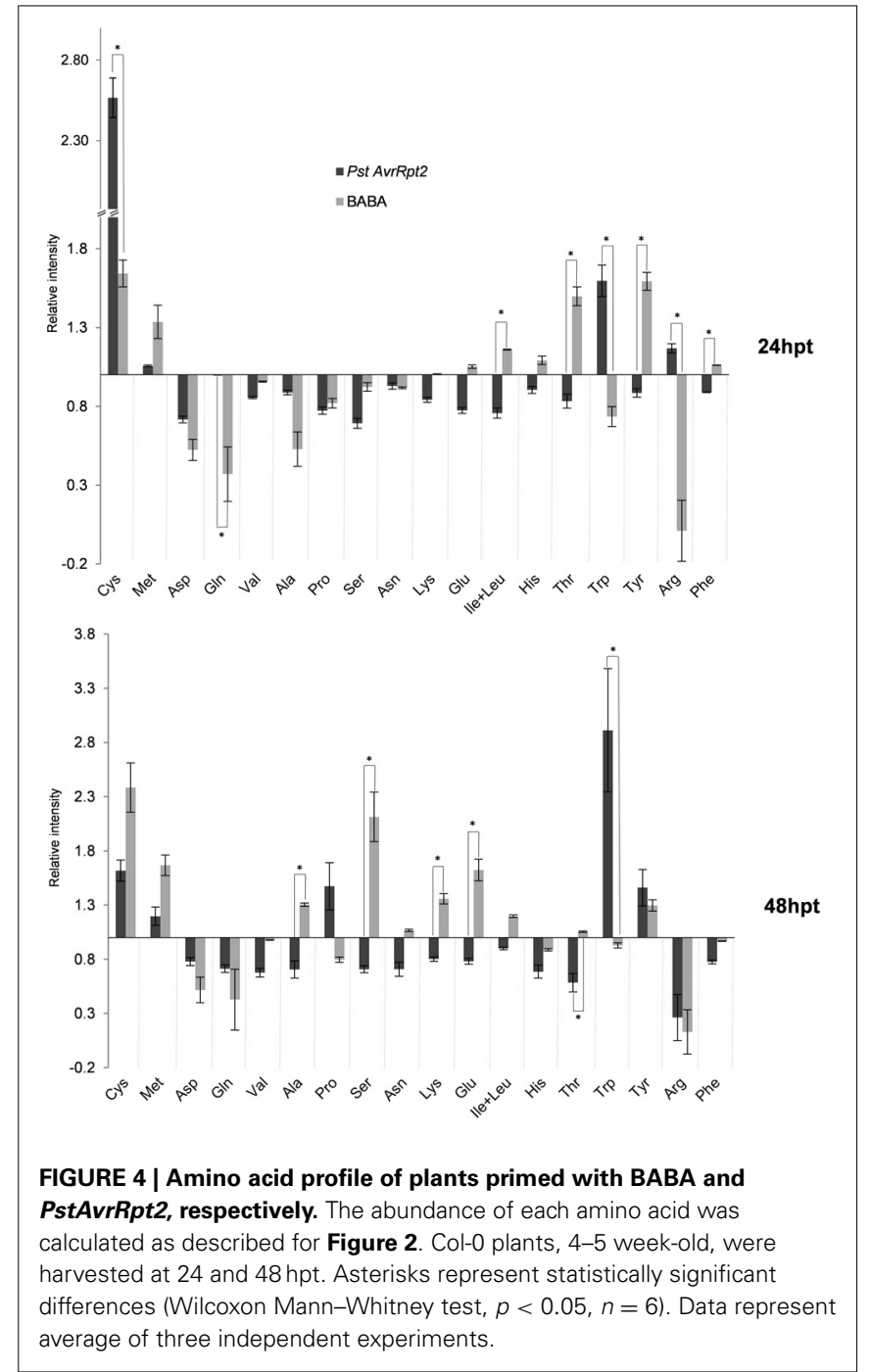

JA levels were repressed at $24 \mathrm{hpt}$ confirming the well-known crosstalk already between SA and JA (Koornneef and Pieterse, 2008). At 48 hpt JA starts to accumulate in BABA-treated plants. OPDA was consistently accumulating over time in BABA-treated plants and depleted by PstAvrRpt 2 treatment in both time points.

Interestingly, Val conjugated to JA (JA-Val) showed a strong accumulation upon BABA treatment and the opposite effect resulted from PstAvrRpt2 treatment at $24 \mathrm{hpt}$. Using exact mass, fragment spectrum and retention time of fragments, some components of the $\alpha$-linolenic and linoleic pathways (octadecanoid pathway) were detected, although in our experimental conditions it was not possible to differentiate between some lipid derivatives due to the similarity between fragments (Figure 7). These compounds are described in Table 1. All of them are precursors of OPDA and JA. The bacteria repressed the $\alpha$-linolenic pathway as well as some compound from the linoleic pathway, such as 13 (S)HODE. After BABA treatment, accumulation was only seen after $48 \mathrm{~h}$ except for 9-(S) HPOT/2(R)-HPOT, which accumulated to a lesser extent. 


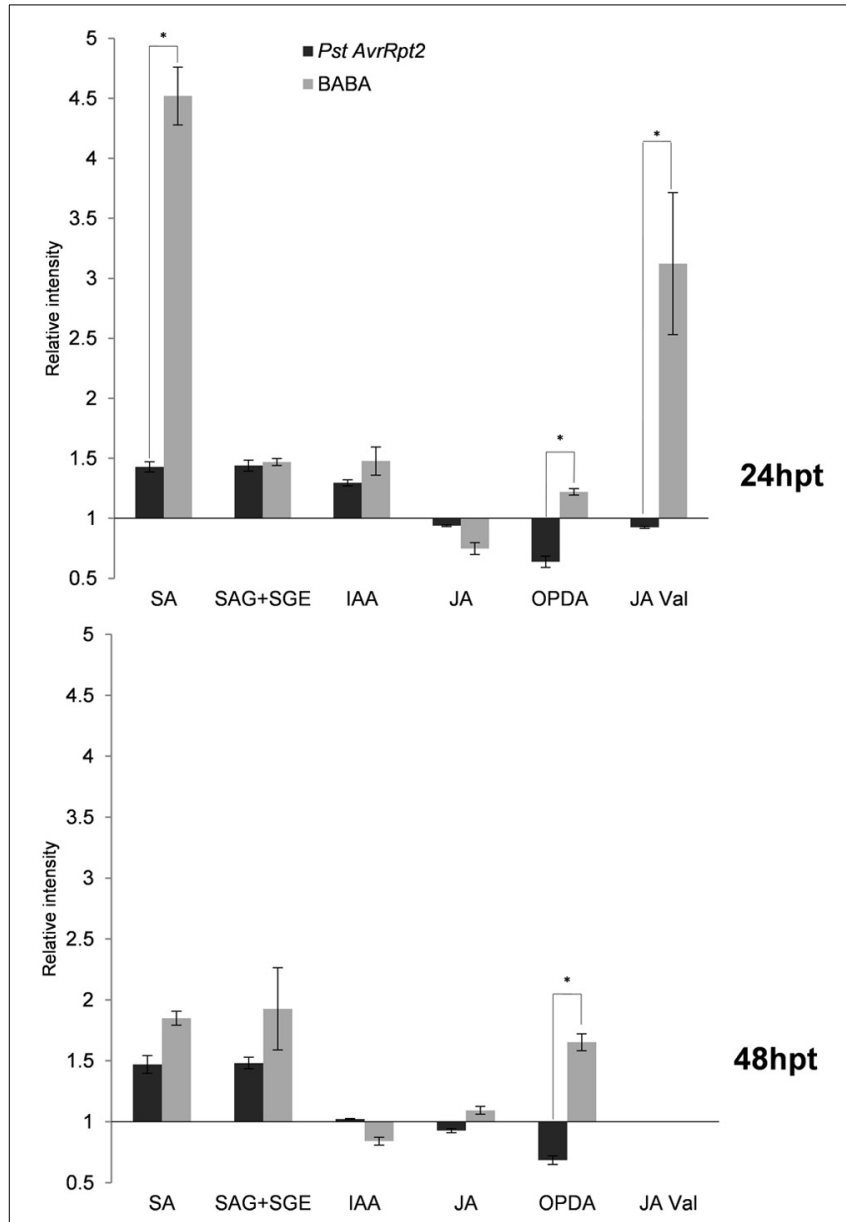

FIGURE 5 | Levels of hormones and conjugates after 24 and $\mathbf{4 8}$ hpt. The abundance of every compound was calculated as in Figure 2. Asterisks represent statistically significant differences (Wilcoxon Mann-Whitney test, $p<0.05, n=6)$. Data represent average of three independent experiments.

Caffeic, cinnamic and ferulic acid were identified using the library of standards (Gamir et al., 2014). At $24 \mathrm{hpt}$ only ferulic acid showed an increase and only upon BABA treatment. At $48 \mathrm{hpt}$ caffeic acid accumulated in BABA-treated plants and the levels of ferulic acid remained as at $24 \mathrm{hpt}$. The bacteria induced the accumulation of cinnamic acid within $48 \mathrm{hpt}$. All these compounds are related to phenylpropanoid biosynthesis pathway (Figure 8). Additional compounds belonging to this pathway have been identified by exact mass like sinapic acid, 1-O-sinapoyl$\beta$-D-glucose and sinapoyl malate. As shown in Figure 8, BABA strongly stimulated the production of sinapic acid and its ester, sinapoyl malate. The glycosylated intermediate compound (1-Osinapoyl- $\beta$-D-glucose) accumulated to a lesser extent following the treatment suggesting that the glycosylated form is feeding into the production of the ester (Milkowski and Strack, 2010).

\section{INVOLVEMENT OF PURINES?}

Interestingly, an additional compound, xanthosine, was induced by both types of priming. This nucleoside was strongly induced, almost to the same levels as citrate and the levels remained high during the entire priming phase following inoculation with

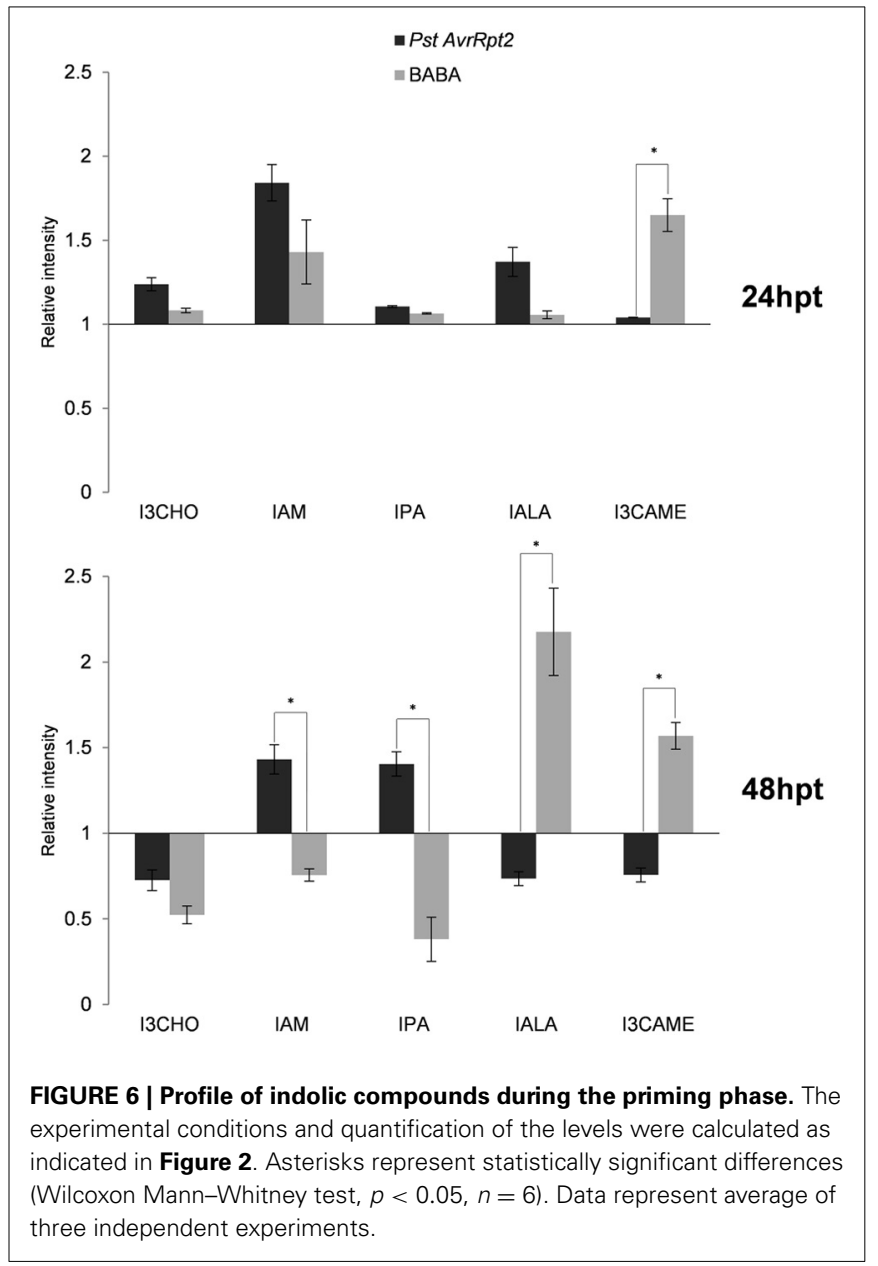

the bacteria (Figure 8). The accumulation of xanthosine was inversely correlated to the one of guanosine. Both compounds play role in purine catabolism, where the amino group of guanosine is released by guanosine deaminase to produce xanthosine (Dahncke and Witte, 2013).

\section{DISCUSSION}

It is crucial for the survival plants to sense changes taking place in their natural environment. Their cells have to adapt the composition and the levels of metabolites to these changes and if the natural balance of metabolites is disturbed, the plant can answer with massive changes at the transcriptional level to recover the equilibrium (Katagiri, 2004; Kresnowati et al., 2006). An adaptation to such environmental changes is facilitated when the plant has been primed to do so. Priming has been described as a sensitized state in which plants can react more adequately to combat stresses. In a primed plant, the speed and the strength of the answer to a given stress is improved, hence, the primed plant survives better and with less damage. The mechanisms underlying priming are still under discussion. The strategies used by primed plants comprise both, relative early as well as long lasting responses (Pastor et al., 2013a). The latter ones have even been shown to be transferred to the offspring (Luna et al., 2012; Rasmann et al., 2012; Slaughter et al., 2012). However, what is 


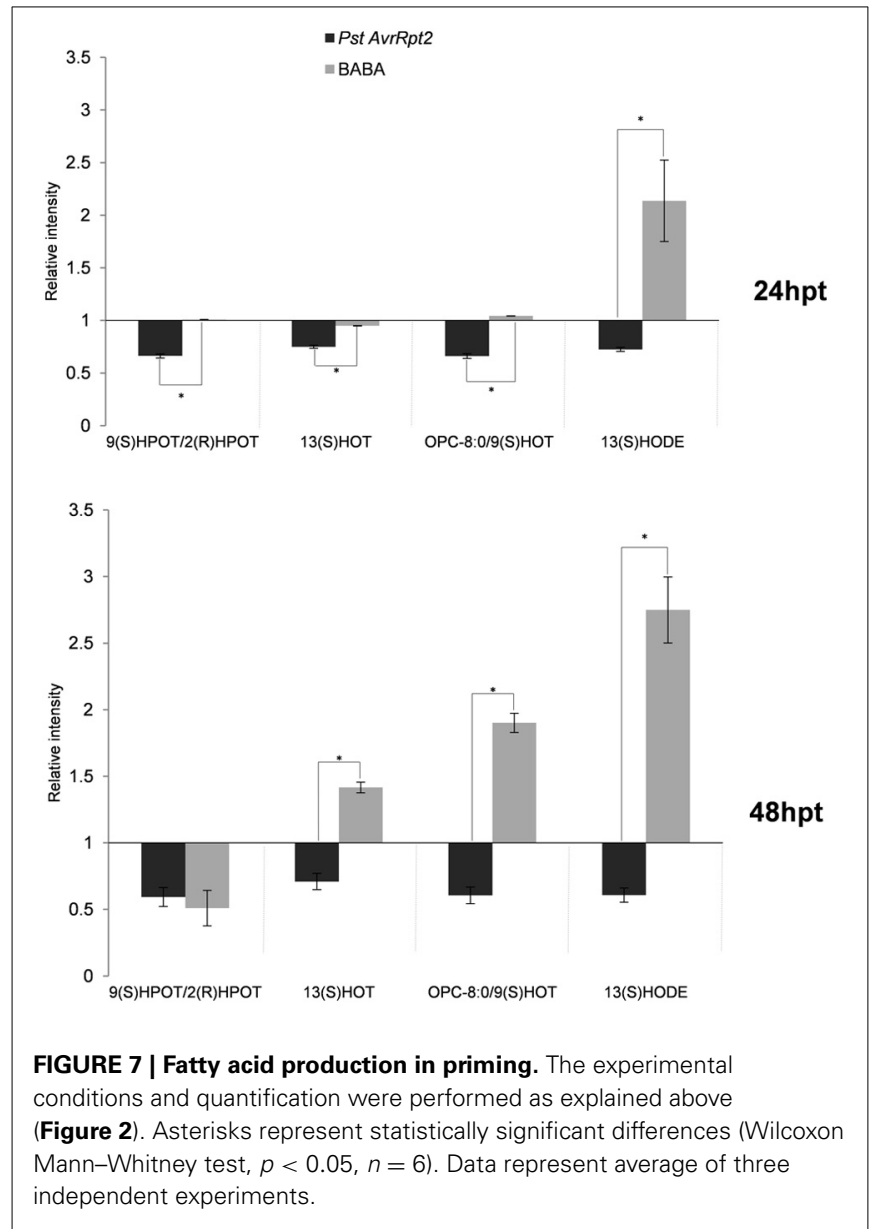

happening in a plant after the perception of a priming cue but prior to encountering the stress remains to be determined. The aim of the present work was to acquire an overview of the metabolites that act as priming compounds and the pathways implicated in the priming phase following treatment of the plants with BABA as a chemical and PstAvrRpt2 as a biological priming agent. Given the nature of priming, i.e., the rapid reaction against any type of stress (biotic and abiotic), the compounds accumulating before challenge with an actual stressor are expected to belong to the very early phase in the chain of events leading to the biochemical synthesis of secondary metabolites.

The comparison of the effect of the priming treatments (BABA and PstAvrRpt2) and their respective control treatments (water and mock,) on the plants' metabolome revealed a different dynamism when comparing BABA- and PstAvrRpt2-primed plants. BABA, as an easily water-soluble chemical, is taken up and distributed rapidly in the plant and might therefore lead to faster changes in the metabolome. On the opposite, the bacteria use quorum sensing to organize and coordinate the interaction between themselves and with their host. PstAvrRpt 2 might need more time to induce changes in the plant since the bacteria have first to multiply in order to colonize the tissues (Miller and Bassler, 2001; Schikora et al., 2011).

The metabolites undergoing the most pronounced changes in BABA-treated plants belong to the tricarboxylic acid (TCA) cycle.

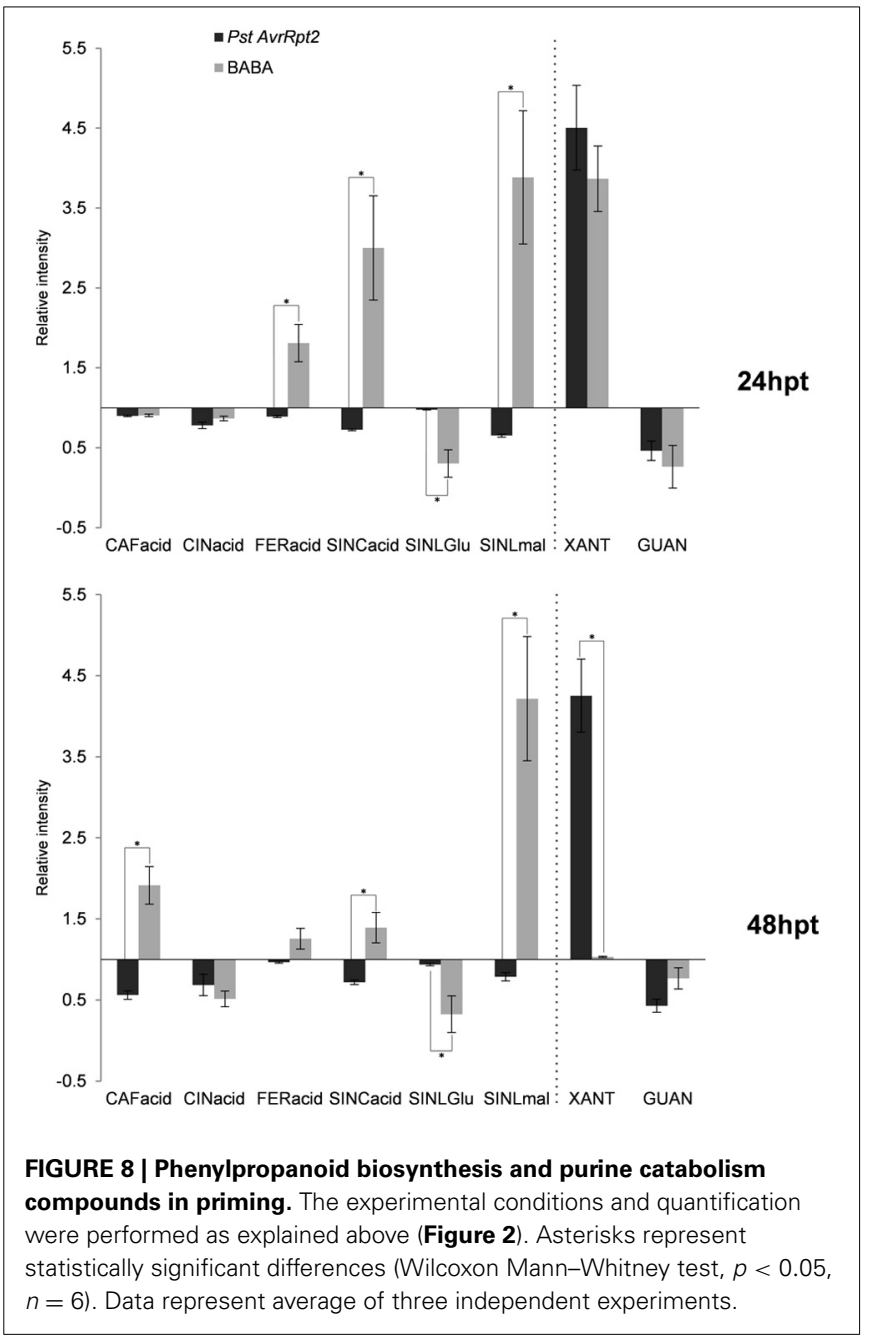

Citrate/isocitrate (indistinguishable in our chromatographic conditions), show the highest accumulation followed by other compounds of the cycle. Only the levels of succinate are reduced by BABA. On the opposite, PstAvrRpt2-treatment leads to a general repression of the TCA cycle. The primary metabolism appears like a key point in priming and highlights the differences between the two kinds of priming inducers.

It is known that both compatible and incompatible interactions lead to a reduction of photosynthesis (Swarbrick et al., 2006; Berger et al., 2007 and references therein) due to the chlorosis provoked by the infection. The reduction of photosynthesis during the resistance responses is accompanied by an increase of carbohydrates in the apoplast and could act as a signal for repression of photosynthesis. The process needs an income of carbon-skeletons that in turn leads to a reduction in the levels of compounds belonging to the TCA cycle (Chou et al., 2000). On the other hand, BABA seems to help in the accumulation of carboxylic acids, perhaps because the plant can perceive the decrease with no apparent reason (no infection) of amino acids following BABA treatment. This could stimulate the production of carboxylic acids (Bolton, 2009) that in turn are not required for other purposes and can be accumulated in order to fuel other 
pathways (Bolton, 2009). It still needs to be investigated whether the accumulation triggered by BABA is a consequence of a minor stress caused by the chemical or if it is a more direct action due to its amino acid nature. The response to stress is accompanied by a wide mobilization of the defense system, nevertheless, not all defense mechanism are used by the plant (Galletti et al., 2008; Rayapuram et al., 2008). In any case, plant response to stress is highly energy-consuming and depends on carbon supply to sustain the biosynthesis of defense compounds. The TCA cycle not only provides such carbon structures for the biosynthesis but also participates in ATP generation. The accumulation of these compounds can help to provide the energy or the carbon skeletons for future demands. The major C sink is to Glu and Gln from citrate and 2-oxoglutarate (Gauthier et al., 2010), but here we found that after BABA-application, only Glu was accumulating over the time of the experiment and this coincided with the induction of 2-oxoglutarate. On the contrary, Gln levels remained low following both types of priming. A possible explanation could be the simultaneous accumulation of the nucleoside xanthosine, a product of the catabolism of purines. The $\mathrm{N}$ structure of the purine ring comes from the Glu, Asp and Gly (Stasolla et al., 2003), and the levels of all three amino acids go markedly down following BABA- and PstAvrRpt2-treatment. The accumulation of xanthosine coincides with the depletion in guanosine. In Arabidopsis, xanthosine is generated from the deamination of guanosine with the help of a specific guanosine deaminase (Dahncke and Witte, 2013). Xanthosine is a precursor of caffeine in some plant species but has not been reported in Arabidopsis (Mohanpuria and Yadav, 2009), and to our knowledge, there is not any direct evidence for a role of this compound in defense. The catabolism of purines ends with the production of $\mathrm{CO}_{2}$ and nitrogen. But purines also participate in building other molecules such as DNA, RNA or other secondary metabolites, and significant amounts of xanthosine are used for RNA synthesis (Ashihara, 2012). This again suggests that the metabolism of primed plants is getting ready for a future need for defense compounds or help in the synthesis of nucleic acids (Riegler et al., 2011).

Secondary metabolism is important for the final output of the defense response, which can produce long distance signals or, even, biocidal substances inhibiting the action of pathogens and insects. During the priming phase, the accumulation of SA and its glycosides, as well as a repression in the accumulation of JA is taking place. Interestingly, there is a peak in SA accumulation at $24 \mathrm{hpt}$ in BABA-treated plants, and this accumulation is significantly higher than the one induced by PstAvrRpt2. After this time point SA remains at the same level in both types of priming. The levels of SA-glycosides do not change during priming and are potentially ready to release free SA upon encounter with a stress. The accumulation of free and conjugated forms of SA after infection with the pathogen Pseudomonas syringae pv tomato DC3000 (Pst; Pastor et al., 2012) has been reported, and this accumulation is usually accompanied by the repression of genes in the JA pathway and related genes (Koornneef and Pieterse, 2008; Boachon et al., 2014). The complexity of SA synthesis and signaling makes it difficult to get an exact picture of all the possible effects it might have in the plant (Shah, 2003). On the other hand, although JA levels display a similar profile in BABA- and PstAvrRpt2-treated plants, the cyclopentenone ODA shows specific behavior depending of the treatment applied. Despite overlapping gene-induction patterns for JA and OPDA (Stinzi et al., 2001), a distinct role for OPDA in signaling can be expected due to the electrophilic nature of the cyclopentenone

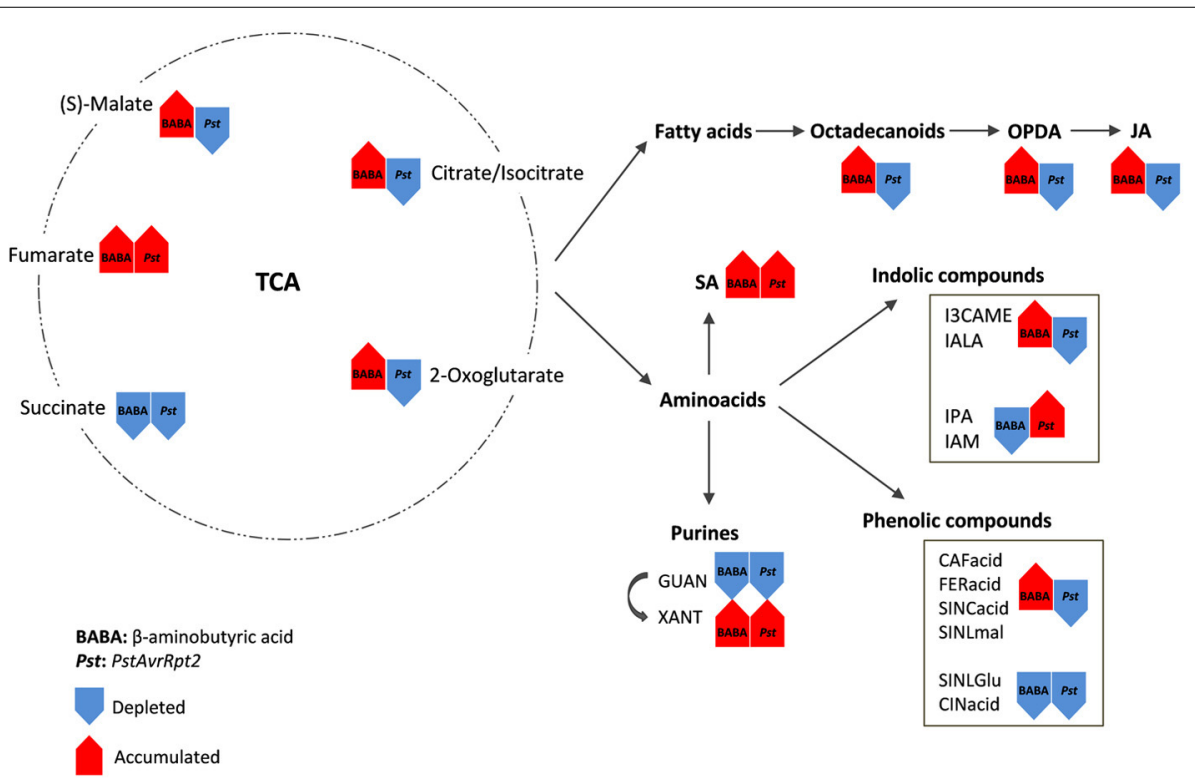

FIGURE 9 | Principal pathways/compounds that show significant changes after the two priming inducers. In priming experiments the stress is usually applied after $48 \mathrm{hpt}$. Rows represent the general changes after this period of time. Red shows the accumulated compounds and blue rows show the depleted compounds/pathways. TCA compounds are the main source for the synthesis of other metabolites playing a major role in defense. These compounds belong to the octadecanoid pathway (fatty acids) and amino acids. Both pathways are divided in subsequent pathways and compounds that are important in defense signaling and decide the final output when the plant meet the stress. 
ring (Farmer et al., 2003). In our experimental conditions, treatment with PstAvrRpt2 altered the oxylipin pathway through the repression of several precursors of OPDA and JA, while these compounds accumulated at $48 \mathrm{hpt}$ with BABA. The repression of the octadecanoid acid pathway by the PstAvrRpt 2 correlates with the observed depletion of tricarboxylic acids and the accumulation of tricarboxylic compounds by BABA correlates well with the induction of the same pathway. This points to a connection between these two pathways. Interestingly, there is a significant increase of the JA conjugate JA-Val. The (+)-JA-Ile conjugate has been shown to be the active isomer in the signaling pathway, but there is little information about the role of other JA-amino acid conjugates. JA-Ile and JA-Val accumulate in response to oral secretions of Manduca sexta mediated by JAR6, a homolog of JAR1, in Nicotiana attenuata,(Wang et al., 2007). In our experimental conditions, an accumulation of JA-Val was only observed at $24 \mathrm{hpt}$, and JA-Ile was not detected. It is conceivable that the conjugation with amino acids leads to an increase of the bioactivity of JA, but further studies are needed to get a clear picture about the role of amino acid conjugates in general defense responses.

The influence of the TCA cycle on the biosynthesis of other biomolecules also linked to the phenylpropanoid biosynthesis. BABA treatment led to an accumulation of sinapate and its ester, sinapoyl malate, while PstAvrRpt 2 treatment caused depletion in these two phenylpropanoids. Thus, BABA has a major impact on this pathway that is supplying precursers of lignin (Goujon et al., 2003). BABA has been shown to play a major role in the modification of the plant cell walls after pathogen attack (Ton and MauchMani, 2004), and it is tempting to hypothesize that phenolics and sinapates act as priming compounds facilitating the synthesis of molecules needed for the reinforcement of the cell wall. A similar mechanism could be imagined for IAA in priming the accumulation of indolic compounds, although both BABA and the bacteria lead to similar accumulation of IAA and the profile of the indolic compounds identified is more variable. Tryptophan (Trp) metabolism leads to the synthesis of glucosinolates, phytoalexins and auxins, and their regulation is dependent on a branched network that makes it difficult to obtain a clear profile. The induction of the Trp pathway by the bacteria is followed by the accumulation of two compounds that participate in IAA synthesis and depend on the Trp pathway, namely indole-3-pyruvic acid (IPA) and indole-3-acetamide (IAM; Strader and Bartel, 2008; Sugawara et al., 2009). Here again, the plants respond differentially to the treatments. While the accumulation of IAA via the Trp pathway seems to be more relevant following priming by PstAvrRpt2, BABA seems to use a Trp-independent pathway (Cohen et al., 2003) since it leads to a depletion of the levels of Trp. Alternatively, it might consume more Trp to produce IAA as well as others conjugates (IALA) or derivatives of indol-3-carboxylates (I3CAME).

The priming state can be installed by certain compounds that supply the material a plant might need when it encounters a stress. Chemical and biological priming each have a certain specificity that prepares the plant in a different manner (Figure 9), but the final result is the same: the survival of the plant. In nature a plant has to decide rapidly which is the best way to respond to unexpected stress. Priming plants for defense gives them the tools to do so by taking the right decision.

\section{ACKNOWLEDGMENTS}

The financial support of the Swiss National Science Foundation, grant 31003A_140593, is gratefully acknowledged. Also we thank the SCIC of the Universitat Jaume I. This work was financially supported by the Plan de Promoción de la InvestigaciónUniversitat Jaume I P1-1B2013-68.

\section{SUPPLEMENTARY MATERIAL}

The Supplementary Material for this article can be found online at: http://www.frontiersin.org/journal/10.3389/fpls.2014.00295/ abstract

\section{Figure S1 | Principal component analysis (PCA) and cluster plots} comparing water and BABA groups generated from the major sources of variable signals obtained in ESI+ and ESI- by non-targeted analysis by HPLC-OTOF MS of the four groups water, BABA, mock, and PstAvrRpt2. The PCA and cluster analyses were performed using Marvis Filter and Cluster packages, following a Kruskal-Wallys test $(p<0.05)$. (A) PCA analysis score plot after $24 \mathrm{hpt}$. (B) Cluster plot of main compounds of the four groups after $24 \mathrm{hpt}$. (C) PCA analysis score plot at $48 \mathrm{hpt}$ (D) Cluster plot of significant compounds after $48 \mathrm{hpt}$.

Figure S2 | Principal component analysis (PCA) and cluster plots comparing the mock and PstAvrRpt2 groups generated from the major sources of variable signals obtained in ESI+ and ESI- by non-targeted analysis by HPLC-OTOF MS of the four groups water, BABA, mock, and PstAvrRpt2. The PCA and cluster analyses were performed using Marvis Filter and Cluster packages, following a Kruskal-Wallys test $(p<0.05)$. (A) PCA analysis score plot after $24 \mathrm{hpt}$. (B) Cluster plot of main compounds of the four groups after $24 \mathrm{hpt}$. (C) PCA analysis score plot at $48 \mathrm{hpt}$. (D) Cluster plot of significant compounds after $48 \mathrm{hpt}$.

\section{REFERENCES}

Ashihara, H. (2012). Xanthosine metabolism in plants: metabolic fate of exogenously supplied 14C-labelled xanthosine and xanthine in intact mungbean seedlings. Phytochem. Lett. 5, 100-103. doi: 10.1016/j.phytol.2011.11.002

Balmer, D., and Mauch-Mani, B. (2013). More beneath the surface? Root versus shoot antifungal plant defenses. Front Plant Sci. 4:256. doi: 10.3389/fpls.2013. 00256

Balmer, D., Villacres de Papajewski, D., Planchamp, C., Glauser, G., and MauchMani, B. (2012). Induced resistance in maize is based on organ-specific defence responses. Plant J. 74, 213-225. doi: 10.1111/tpj.12114

Barth, C., and Jander, G. (2006). Arabidopsis myrosinases TGG1 and TGG2 have redundant function in glucosinolates breakdown and insect defense. Plant J. 46, 549-562. doi: 10.1111/j.1365-313X.2006.02716.x

Beckers, G. J. M., Jaskiewicz, M., Liu, Y., Underwood, W. R., He, S. Y., Zhang, S., et al. (2009). Mitogen-activated protein kinases 3 and 6 are required for full priming of stress responses in Arabidopsis thaliana. Plant Cell 21, 944-953. doi: 10.1105/tpc.108.062158

Bednarek, P., Piślewska-Bednarek, M., Svatoš, A., Schneider, B., Doubský, J., Mansurova, M., et al. (2009). A glucosinolates metabolism pathway in living plant cells mediates broad-spectrum antifungal defense. Science 323, 101-106. doi: 10.1126/science.1163732

Berger, S., Sinha, A. K., and Roitsch, T. (2007). Plant physiology meets phytopathology: plant primary metabolism and plant-pathogen interactions. J. Exp. Bot. 58, 4019-4026. doi: 10.1093/jxb/erm298

Berr, A., McCallum, E. J., Alioua, A., Heintz, D., Heitz, T., and Shen, W.-H. (2010). Arabidopsis histone methyltransferase set domain group 8 mediates induction of the jasmonate/ethylene pathway genes in plant defence response to necrotrophic fungi. Plant Physiol. 154, 1403-1414. doi: 10.1104/pp.110. 161497

Boachon, B., Gamir, J., Pastor, V., Erb, M., Dean, J. V., Flors, V., et al. (2014). Role of two UDP-Glycosyltransferases from the F group of Arabidopsis in resistance 
against Pseudomonas syringae. Eur. J. Plant Pathol. doi: 10.1007/s10658-0140424-7. [Epub ahead of print].

Bolton, M. D. (2009). Primary metabolism and plant defense- fuel for the fire. Mol. Plant-Microbe Interact. 22, 487-497. doi: 10.1094/MPMI-22-5-0487

Bruce, T. J. A., Matthes, M. C., Napier, J. A., and Pickett, J. A. (2007). Stressful memories of plants: evidence and possible mechanisms. Plant Sci. 173, 603-608. doi: 10.1016/j.plantsci.2007.09.002

Chou, H.-M., Bundock, N., Rolfe, S. A., and Scholes, J. D. (2000). Infection of Arabidopsis thaliana leaves with Albugo candida (white blister rust) causes a reprogramming of host metabolism. Mol. Plant Pathol. 1, 99-113. doi: 10.1046/j.1364-3703.2000.00013.x

Cohen, J. D., Slovin, J. P., and Hendrickson, A. M. (2003). Two genetically discrete pathways convert tryptophan to auxin: more redundancy in auxin biosynthesis. Trends Plant Sci. 8, 197-199. doi: 10.1016/S1360-1385(03)00058-X

Cohen, Y. R. (2002). Beta-aminobutyric acid-induced resistance against plant pathogens. Plant Dis. 86, 448-457. doi: 10.1094/PDIS.2002.86.5.448

Conrath, U. (2009). Priming of induced plant defense responses. Adv. Bot. Res. 51, 362-395. doi: 10.1016/S0065-2296(09)51009-9

Conrath, U. (2011). Molecular aspects of defence priming. Trends Plant Sci. 16, 524-531. doi: 10.1016/j.tplants.2011.06.004

Conrath, U., Pieterse, C. M. J., and Mauch-Mani, B. (2002). Priming in plantpathogen interactions. Trends Plant Sci. 7, 210-216. doi: 10.1016/S13601385(02)02244-6

Dahncke, K., and Witte, C. P. (2013). Plant purine nucleoside catabolism employs a guanosine deaminase required for the generation of xanthosine in Arabidopsis. Plant Cell 25, 4101-4109. doi: 10.1105/tpc.113.117184

Dean, J., and Mills, J. (2004). Uptake of salicylic acid 2-O-beta-d-glucose into soybean tonoplast vesicles by an ATP-binding cassette transporter-type mechanism. Physiol. Plant. 120, 603-612. doi: 10.1111/j.0031-9317.2004.0263.x

Dean, J., Mohammed, L., and Fitzpatrick, T. (2005). The formation, vacuolar localization, and tonoplast transport of salicylic acid glucose conjugates in tobacco cell suspension cultures. Planta 221, 287-296. doi: 10.1007/s00425-004-1430-3

Durrant, W. E., and Dong, X. (2004). Systemic acquired resistance. Annu. Rev. Phytopathol. 42,185-209. doi: 10.1146/annurev.phyto.42.040803.140421

Ebel, J., and Cosio, E. G. (1994). Elicitors of plant defense responses. Int. Rev. Cytol. 148, 1-36. doi: 10.1016/S0074-7696(08)62404-3

Edwards, R. (1994). Conjugation and metabolism of salicylic acid in tobacco. J. Plant Physiol. 143, 609-614. doi: 10.1016/S0176-1617(11)81146-6

Farmer, E. E., Alméras, E., and Krishnamurthy, V. (2003). Jasmonates and related oxylipins in plant responses to pathogenesis and herbivory. Curr. Opin. Plant Biol. 6, 372-378. doi: 10.1016/S1369-5266(03)00045-1

Fernie, A. R., Aharoni, A., Willmitzer, L., Stitt, M., Tohge, T., Kopka, J., et al. (2011). Recommendations for reporting metabolite data. Plant Cell. 23, 2477-2482. doi: 10.1105/tpc.111.086272

Flors, V., Ton, J., Van Doorn, R., Jakab, G., Garcia-Agustin, P., and Mauch-Mani, B. (2008). Interplay between JA, SA and ABA signalling during basal and induced resistance against Pseudomonas syringae and Alternaria brassicicola. Plant J. 54, 81-92. doi: 10.1111/j.1365-313X.2007.03397.x

Fonseca, S., Chini, A., Hamberg, M., Adie, B., Porzel, A., Miersch, O., et al. (2009). (+)-7-iso.jasmonoyl-L-isoleucine is de endogenous bioactive jasmonate. Nat. Chem. Biol. 5, 344-350. doi: 10.1038/nchembio.161

Galletti, R., Denoux, C., Gambetta, S., Dewdney, J., Ausubel, F., De Lorenzo, G., et al. (2008). The AtrbohD-mediated oxidative burst elicited by oligogalacturonides in Arabidopsis is dispensable for the activation of defense responses effective against Botrytis cinerea. Plant Physiol. 148, 1695-1706. doi: 10.1104/pp.108.127845

Gamir, J., Pastor, V., Cerezo, M., and Flors, V. (2012). Identification of indole-3carboxylic acid as mediator of priming against Plecthosphaerella cucumerina. Plant Physiol. Biochem. 61,169-179. doi: 10.1016/j.plaphy.2012.10.004

Gamir, J., Pastor, V., Kaever, A., Cerezo, M., and Flors, V. (2014). Targeting novel chemical and constitutive primed metabolites against Plectosphaerella cucumerina. Plant J. 78, 227-240. doi: 10.1111/tpj.12465

Garcia-Andrade, J., Ramirez, V., Flors, V., and Vera, P. (2011). Arabidopsis ocp3 mutant reveals a mechanism linking ABA and JA to pathogen-induced callose deposition. Plant J. 67, 783-794. doi: 10.1111/j.1365-313X.2011.04633.x

Gauthier, P. G., Bligny, R., Gout, E., Mahé, A., Nogués, S., Hodges, M., et al. (2010). In folio isotopic tracing demonstrates that nitrogen assimilation into plutamate is mostly dependent from current $\mathrm{CO} 2$ assimilation in illuminated leaves of Brassica napus. New Phytol. 185, 988-999. doi: 10.1111/j.1469-8137.2009. 03130.x
Glazebrook, J. (2005). Contrasting mechanisms of defense against biotrophic and necrotrophic pathogens. Ann. Rev. Phytopathol. 43, 205-227. doi: 10.1146/annurev.phyto.43.040204.135923

Goujon, T., Sibout, R., Pollet, B., Maba, B., Nussaume, L., Bechtold, N., et al. (2003) A new Arabidopsis thaliana mutant deficient in the expression of O-methyltransferase impacts lignins and sinapoyl esters. Plant. Mol. Biol. 51, 973-989. doi: 10.1023/A:1023022825098

Hamiduzzaman, M. Md., Jakab, G., Barnavon, L., Neuhaus, J. M., and MauchMani, B. (2005). $\beta$-Aminobutyric acid-induced resistance against downy mildew in grapevine acts through the potentiation of callose formation and jasmonic acid signaling. Mol. Plant Microbe Int. 18, 819-889. doi: 10.1094/MPMI18-0819

Hammerschmidt, R. (2009). Systemic acquired resistance. Adv. Bot. Res. 51, 173-222. doi: 10.1016/S0065-2296(09)51005-1

Jakab, G., Cottier, V., Toquin, V., Rigoli, G., Zimmerli, L., Metraux, J. P., et al. (2001). Aminobutiric acid-induced resistance in plants. Eur. J. Plant Pathol. 107, 29-37. doi: 10.1023/A:1008730721037

Jakab, G., Ton, J., Flors, V., Zimmerli, L., Métraux, J. P., and Mauch-Mani, B. (2005). Enhancing Arabidopsis salt and drought stress tolerance by chemical priming for its abscisic acid responses. Plant Phsyiol. 139,267-274. doi: 10.1104/pp.105.065698

Jaskiewicz, M., Conrath, U., and Peterhansel, C. (2011). Chromatin modification acts as a memory for systemic acquired resistance in the plant stress response. EMBO Rep. 12, 50-55. doi: 10.1038/embor.2010.186

Jones, D. A., and Takemoto, D. (2004). Plant innate immunity - direct and indirect recognition of general and specific pathogen-associated molecules. Curr. Opin. Immun. 16, 48-62. doi: 10.1016/j.coi.2003.11.016

Jones, J., and Dangl, J. L. (2006). The plant immune system. Nature 444, 323-329. doi: $10.1038 /$ nature 05286

Jung, H. W., Tschaplinski, T. J., Wang, L., Glazebrook, J., and Greenberg, J. T. (2009). Priming in systemic plant immunity. Science 324, 89-91. doi: 10.1126/science. 1170025

Kaever, A., Landesfeind, M., Possienke, M., Feussner, K., Feussner, I., and Meinicke, P. (2012). MarVis-filter: ranking, filtering, adduct and isotope correction of mass spectrometry data. J. Biom. Biotechol. 2012:263910. doi: 10.1155/2012/ 263910

Kaiser, G., Weiler, E., and Hartung, W. (1985). The intracellular distribution of abscisic acid in mesophyll cells - the role of the vacuole. J. Plant Physiol. 119, 237-245. doi: 10.1016/S0176-1617(85)80183-8

Katagiri, F. (2004). A global view of defense gene expression regulation-a highly interconnected signaling network. Curr. Opin. Plant Biol. 7, 506-511. doi: 10.1016/j.pbi.2004.07.013

Koornneef, A., and Pieterse, C. M. J. (2008). Cross talk in defense signaling. Plant Physiol. 146, 839-844. doi: 10.1104/pp.107.112029

Kresnowati, M. T. A. P., van Widen, W. A., Almering, H. J. H., Pierick, A., Ras, C., Knijnenburg, T. A., et al. (2006). When transcriptome meets metabolome: fast cellular responses of yeast to sudden relief of glucose limitation. Mol. Syst. Biol. 2:49. doi: $10.1038 / \mathrm{msb} 4100083$

Lee, H., and Raskin, I. (1998). Glucosylation of salicylic acid in Nicotiana tabacum cv Xanthi-nc. Phytopathology 88, 692-697. doi: 10.1094/PHYTO.1998.88.7.692

Lee, H., and Raskin, I. (1999). Purification, cloning, and expression of a pathogen inducible UDP-glucose: salicylic acid glucosyltransferase from tobacco. J. Biol. Chem. 274, 36637-36642. doi: 10.1074/jbc.274.51.36637

Li, T., Chen, X., Zhong, X., Zhao, Y., Liu, X., Zhou, S., et al. (2013). Jumonji C domain protein JMJ705-mediated removal of histone $\mathrm{H} 3$ lysine 27 trimethylation is involved in defense-related gene activation in rice. Plant Cell 25, 4725-4736. doi: 10.1105/tpc.113.118802

Liu, G., Ji, Y., Bhuiyan, N. H., Pilot, G., Selvaraj, G., Zou, J., et al. (2010). Aminoacid homeostasis modulates salycilic acid-associated redox status and defense responses in Arabidopsis. Plant Cell 22, 3845-3863. doi: 10.1105/tpc.110.079392

Luna, E., Bruce, T. J., Roberts, M. R., Flors, V., and Ton, J. (2012). Next generation systemic acquired resistance. Plant Physiol. 158, 844-853. doi: 10.1104/pp.111.187468

Milkowski, C., and Strack, D. (2010). Sinapate esters in brassicaceous plants: biochemistry, molecular biology, evolution and metabolic engineering. Planta 232, 19-35. doi: 10.1007/s00425-010-1168-z

Miller, M. B., and Bassler, B. L. (2001). Quorum sensing in bacteria. Annu. Rev. Microbiol. 55, 165-199. doi: 10.1146/annurev.micro.55.1.165

Mohanpuria, P., and Yadav, S. K. (2009). Retardation in seedling growth and induction of early senescence in plants upon caffeine exposure is related to its negative 
effect on Rubisco. Photosynthetica 47, 293-297. doi: 10.1007/s11099-0090045-0

Moller, I. M., Jensen, P. E., and Hansson, A. (2007). Oxidative modifications to cellular components in plants. Annu. Rev. Plant Biol. 58, 459-481. doi: 10.1146/annurev.arplant.58.032806.103946

Morant, A. V., Jorgensen, K., Jorgensen, C., Paquette, S. M., Sanchez-Perez, R., Moller, B. L., et al. (2008). $\beta$-Glucosidases as detonators of plant chemical defence. Phytochemistry 69, 1795-1813. doi: 10.1016/j.phytochem.2008. 03.006

Mudgett, M. B., and Staskawicz, B. J. (1999). Characterization of the Pseudomonas syringae pv. tomato AvrRpt2 protein: demonstration of secretion and processing during bacterial pathogenesis. Mol. Microbiol. 32, 927-941. doi: 10.1046/j.13652958.1999.01403.x

Návarová, H., Bernsdorff, F., Döring, A. C., and Zeier, J. (2012). Pipecolic acid, an endogenous mediator of defence amplification and priming, is acritical regulator of inducible plant immunity. Plant Cell 24, 5123-5141. doi: 10.1105/tpc.112.103564

Nimchuk, Z., Eulgem, T., Holt III, B. F., and Dangl, J. F. (2003). Recognition and response in the plant immune system. Ann. Rev. Genet. 37, 579-609. doi: 10.1146/annurev.genet.37.110801.142628

Noutoshi, Y., Okazaki, M., Kida, T., Nishina, Y., Morishita, Y., Ogawa, T., et al. (2012). Novel plant immune-priming compounds identified via highthroughput chemical screening target salicylic acid glucosyltransferases in Arabidopsis. Plant Cell 24, 3795-3804. doi: 10.1105/tpc.112.098343

Nürnberger, T., and Lipka, V. (2005). Non-host resistance in plants: new insights into an old phenomenon. Mol. Plant Pathol. 6, 335-345. doi: 10.1111/j.13643703.2005.00279.x

Oostendorp, M., Kunz,W., Dietrich, B., and Staub, T. (2001). Induced disease resistance in plants by chemicals. Europ. J. Plant Pathol. 107, 19-28. doi: 10.1023/A:1008760518772

Pastor, V., Luna, E., Mauch-Mani, B., Ton, J., and Flors, V. (2013a). Primed plants do not forget. Environ. Exp. Bot. 94, 46-56. doi: 10.1016/j.envexpbot.2012. 02.013

Pastor, V., Luna, E., Ton, J., Cerezo, M., García-Agustín, P., and Flors, V. (2013b). Fine tuning of reactive oxygen species homeostasis regulates primed immune responses in Arabidopsis. Mol. Plant-Microbe Interact. 26, 1334-1344. doi: 10.1094/MPMI-04-13-0117-R

Pastor, V., Vicent, C., Cerezo, M., Mauch-Mani, B., Dean, J., and Flors, V. (2012). Detection, characterization and quantification of salicylic acid conjugates in plant extracts by ESI tandem mass spectrometric techniques. Plant Physiol. Bioch. 53, 19-26. doi: 10.1016/j.plaphy.2012.01.003

Prime-A-Plant Group., Conrath, U., Beckers, G. J. M., Flors, V., García-Agustín, P., Jakab, G., et al. (2006). Priming: getting ready for battle. Mol. Plant Microbe Interact. 19, 1062-1071. doi: 10.1094/MPMI-19-1062

Rasmann, S., De Vos, M., Casteel, C. L., Tian, D., Halitschke, R., Sun, J. Y., et al. (2012). Herbivory in the previous generation primes Arabidopsis and tomato for enhanced insect resistance. Plant Physiol. 158, 854-863. doi: 10.1104/pp.111.187831

Rayapuram, C., Wu, J., Haas, C., and Baldwin, I. T. (2008). PR-13/Thionin but not PR-1 mediates bacterial resistance in Nicotiana attenuate in nature, and neither influences herbivore resistance. Mol. Plant-Microbe Interact. 21, 988-1000. doi: 10.1094/MPMI-21-7-0988

Riegler, H., Geserick, C., and Zrenner, R. (2011). Arabidopsis thaliana nucleosidase mutants provide new insights into nucleoside degradation. New Phytol. 191, 349-359. doi: 10.1111/j.1469-8137.2011.03711.x

Sauter, A., Dietiz, J. K., and Hartung, W. (2002). A possible stress physiological role of abscisic acid conjugates in root-to-shoot signalling. Plant Cell Environ. 25, 223-228. doi: 10.1046/j.1365-3040.2002.00747.x

Schikora, A., Schenk, S. T., Stein, E., Molitor, A., Zuccaro, A., and Kogel, K. H. (2011). N-acyl-homoserine lactone confers resistance toward biotrophic and hemibiotrophic pathogens via altered activation of AtMPK6. Plant Physiol. 157, 1407-1418. doi: 10.1104/pp.111.180604

Seo, S., Ishizuka, K., and Ohashi, Y. (1995). Induction of salicylic acid betaglucosidase in tobacco leaves by exogenous salicylic acid. Plant Cell Physiol. 36, $447-453$.

Shah, J. (2003). The salicylic acid loop in plant defense. Curr. Opin. Plant Biol. 6, 365-371. doi: 10.1016/S1369-5266(03)00058-X

Singh, P., Wu, C. C., and Zimmerli, L. (2010). Beta-aminobutyric acid priming by stress imprinting. Plant Signal. Behav. 5, 878-880. doi: 10.4161/psb.5.7.11903
Slaughter, A., Daniel, X., Flors, V., Luna, E., Hohn, E., and Mauch-Mani, B. (2012). Descendants of primed Arabidopsis plants exhibit resistance to biotic stress. Plant Physiol. 158, 835-843. doi: 10.1104/pp.111.191593

Smith, C. A., Want, E. J., O'Maille, G., Abagyan, R., and Siuzdak, G. (2006). XCMS processing mass spectrometry data for metabolite profiling using nonlinear peak alignment, matching, and identification. Anal. Chem. 78, 779-787. doi: 10.1021/ac051437y

Song, J. T. (2006). Induction of a salicylic acid glucosyltransferase, AtSGT1, is an early disease response in Arabidopsis thaliana. Mol. Cells 22, 233-238.

Stasolla, C., Katahira, R., Thorpe, T. A., and Ashihara, H. (2003). Purine and pyrimidine nucleotide metabolism in higher plants. J. Plant Physiol. 160, 1271-1295. doi: 10.1078/0176-1617-01169

Stinzi, A., Weber, H., Reymond, P., Browse, J., and Farmer, E. E. (2001). Plant defense in the absence of jasmonic acid: the role of cyclopentenones. Proc. Natl. Acad. Sci. U.S.A. 98, 12897-12842. doi: 10.1073/pnas.211311098

Strader, L. C., and Bartel, B. (2008). A new path to auxin. Nat. Chem. Biol. 4, 337-339. doi: 10.1038/nchembio0608-337

Sugawara, S., Hishiyama, S., Jikumaru, Y., Hanada, A., Nishimura, T., Koshiba, T., et al. (2009). Biochemical analyses of indole-3-acetaldoxime-dependent auxin biosynthesis in Arabidopsis. Proc. Natl. Acad. Sci. U.S.A. 106, 5430-5435. doi: 10.1073/pnas.0811226106

Swarbrick, P. J., Schulze-Lefert, P., and Scholes, J. D. (2006). Metabolic consequences of susceptibility and resistance (race-specific and broad-spectrum) in barley leaves challenged with powdery mildew. Plant Cell Environ. 29, 1061-1076. doi: 10.1111/j.1365-3040.2005.01472.x

Ton, J., Flors, V., and Mauch-Mani, B. (2009). The multifaceted role of ABA in disease resistance. Trends Plant Sci. 14, 310-317. doi: 10.1016/j.tplants.2009.03.006

Ton, J., and Mauch-Mani, B. (2004). $\beta$-Amino-butyric acid-induced resistance against necrotrophic pathogens is based on ABA-dependent priming for callose. Plant J. 38, 119-130. doi: 10.1111/j.1365-313X.2004.02028.x

Trouvelot, S., Varnier, A., Allegre, M., Mercier, L., Baillieul, F., Arnould, C., et al. (2008). A $\beta-1,3$ glucan sulfate induces resistance in grapevine against Plasmopara viticola through priming of defense responses, including HR-like cell death. Mol. Plant Microbe Interact. 21, 232-243. doi: 10.1094/MPMI-21-2-0232

van den Burg, H. A., and Takken, F. L. W. (2009). Does chromatin remodeling mark systemic acquired resistance? Trends Plant Sci. 14, 286-294 doi: 10.1016/j.tplants.2009.02.003

Van der Ent, S., Van Hulten, M., Pozo, M. J., Czechowski, T., Udvardi, M. K., Pieterse, C. M. J., et al. (2009). Priming of plant innate immunity by rhizobacteria and $\beta$-aminobutyric acid: differences andsimilarities in regulation. New Phytol. 183, 419-431. doi: 10.1111/j.1469-8137.2009.02851.x

van Loon, L. C., Bakker, P. A. H. M., and Pieterse, C. M. J. (1998). Systemic resistance induced by rhizosphere bacteria. Ann. Rev. Phytopathol. 36, 453-483.

Wang, L., Halitschke, R., Kang, J. H., Berg, A., Harnisch, F., and Baldwin, I. T. (2007). Independently silencing two JAR family members impairs levels of trypsin proteinase inhibitors but not nicotine. Planta 226, 159-167. doi: 10.1007/s00425-007-0477-3

Zeier, J. (2013). New insights into the regulation of plant immunity by amino acid metabolic pathways. Plant Cell Environ. 36, 2085-2103. doi: 10.1111/pce.12122

Zimmerli, L., Jakab, G., Métraux, J. P., and Mauch-Mani, B. (2000). Potentiation of pathogen-specific defence mechanisms in Arabidopsis by $\beta$-aminobutyric acid. Proc. Natl. Acad. Sci. U.S.A. 97, 12920-12925. doi: 10.1073/pnas.230416897

Conflict of Interest Statement: The authors declare that the research was conducted in the absence of any commercial or financial relationships that could be construed as a potential conflict of interest.

Received: 07 April 2014; accepted: 06 June 2014; published online: 24 June 2014. Citation: Pastor V, Balmer A, Gamir J, Flors V and Mauch-Mani B (2014) Preparing to fight back: generation and storage of priming compounds. Front. Plant Sci. 5:295. doi: $10.3389 / f p l s .2014 .00295$

This article was submitted to Plant Physiology, a section of the journal Frontiers in Plant Science.

Copyright $\odot 2014$ Pastor, Balmer, Gamir, Flors and Mauch-Mani. This is an openaccess article distributed under the terms of the Creative Commons Attribution License (CC BY). The use, distribution or reproduction in other forums is permitted, provided the original author(s) or licensor are credited and that the original publication in this journal is cited, in accordance with accepted academic practice. No use, distribution or reproduction is permitted which does not comply with these terms. 